If we are prepared to accept this view it would seem reasonable to treat any case of accessible intra-ocular șarcoma by the foregoing means where the growth has not as yet seriously spoiled the eye, and in the rare cases where the growth occurs in an only eye or in an eye which is the only useful eye it would seem the proper treatment to adopt. It is, however, clearly impossible to make any dogmatic statement at this stage and further experience must be awaited.

The fact that dissemination may already have taken place before the seed was inserted makes it additionally difficult to form a sound judgment. I have known a patient die of dissemination twelve years after the removal of an eye for melanotic sarcoma, and without any local recurrence, and in such a case it seems necessary to suppose that dissemination occurred twelve years before causing death but had remained latent. (Roy. Lond. Ophthal. Hosp. Reps., 1914, XIX, Part III, 421.)

With regard to technique it may be stated that it is not difficult to insert, and afterwards to remove, a radon seed from the substance of some cases at least of intra-ocular melanotic sarcoma without causing intra-ocular haemorrhage or any other complication, and I have since shown in other cases that this can be done even though the tumour is so far back as to be close to the optic disc.

With regard to the strength of seed that should be used it would seem that 1 millicurie is insufficient, that 5 millicuries may safely be used and experience may prove that a greater strength is preferable.

\title{
SARCOMA OF THE IRIS
}

BY

M. S. MaYOU

LONDON

Sarcoma of the iris is a rare disease. There are about 100 cases on record. The growths may be pigmented or unpigmented. The four cases described below all belong to the former group. Of the pigmented group there are those which definitely start in large pigmented naevi which have been noted to be present beforehand, or those which are supposed to have started in the stroma of the iris. In nearly all the cases the tumour consists of large spindle cells to which the cases recorded below are no exception. These large spindle cells are characteristic of growths derived from naevi and it is probable that most of the tumours which are recorded as having been derived from the stroma of the iris may have had their origin from small naevi of the iris which have not been noted beforehand. Coats (Trans. Ophthal. Soc. U.K., Vol. XXXII, 
page 165) collected 26 cases of innocent naevi out of which 7 had become malignant whilst under observation.

The disease is most frequent between the ages of 35 and 55 and according to statistics a little commoner in females than in males, the lower half of the iris being more frequently affected than the upper. It is often difficult to tell whether the tumour starts at the root of the iris or in the neighbourhood of the ligamentum peetinatum of the ciliary body since the latter becomes rapidly involved in the growth (Cases III and IV). They present themselves under varying clinical appearances. If starting in a definite pigmented naevus as in Case 1, the malignancy becomes manifest by increase in the size of the tumour, whereas if starting in the deeper layers of the iris near its root the tumour may spread beneath the stroma of the iris causing discoloration as in Case II. The colour of the tumour when on the surface of the iris may be brown as in Case I, or deep black in colour as in Case III. The tendency of the growth to spread into the fibres of the ligamentum pectinatum and canal of Schlemm gives rise to an early rise of tension in the course of the disease (Cases I, II, and IV), and there is a strong tendency for the disease to spread around the angle of the chamber. This was very marked in Case II, which belongs to the type known as ring sarcoma of the iris, cases of which have been published by Werner (Trans. Ophthal. Soc. U.K., Vol. XXV, p. 266), Parsons (Arch.f. Ophthal., Vol. XXXIII, 1904, p. 101), A. Brun (Arch. of Ophthal., Vol. LIII, p. 162), and T. M. Li (Amer. Jl. of Ophthal., 1923, p. 545). In other cases such as Case III, the angle of the chamber does not become "sown" with malignant pigment cells and the growth may attain a large size without glaucoma supervening.

\section{Case I. Large Pigmented Naevus of the Iris becoming malignant}

The Rev. R. first seen by me on September 10, 1915, with a mass on his iris which he had had for some years, but " thinks it has been slightly growing lately." The growth is situated on the outer side and a little below the horizontal meridian. It slightly overlaps the pupil and has a heaped up somewhat convoluted appearance on the surface. There is a little peppered pigment on the surface of the iris between it and the angle of the chamber and there are one or two pigmented spots in the iris tissue elsewhere (see Plate I). The vision of the eye was 6/6. It was watched and as no change took place in the growth nothing was done. Last seen on December 1, 1922 .

On May 22, 1928, thirteen years after he was first seen, he was sent up to me by Mr. Maddox; the spongy-looking growth had 
increased in size, had blocked the filtration angle and was against the back of the cornea, causing disturbance in Descemet's membrane over a small area. The tension was raised to +1 , but the cornea was not steamy. (See Plate II.) The eye was removed.

\section{Pathological Examination.}

The tumour involved the whole breadth of the iris in the sector in which it was situated, bulging forwards against the posterior surface of the cornea and backwards protruding through the posterior pigment layer of the iris about its centre. At the angle of the chamber the growth invaded the canal of Schlemm and had extended around for the greater part of its circumference and involved the fibres of the ligamentum pectinatum; it was also beginning to extend backwards into the ciliary body. The growth consisted of large cells of the endothelial type such as are usually found in naevi together with large quantities of pigment cells. The pigment was irregularly scattered throughout the growth either in the form of scattered cells or large masses of pigment. The growth was very vascular and contained large lymphatic spaces. There is no doubt that the tumour was a large pigmented naevus of the iris just becoming malignant and invading the canal of Schlemm and ciliary body. (Figs. 1, 2, 3.)

A somewhat similar case to this has been recorded by $\mathrm{E}$. T. Collins (Trans. Ophthal. Soc. U.K., Vol. XLVI, p. 108).

\section{Case II. Mr. Tudor Thomas's Case Ring Sarcoma of the Iris}

L. E. N., aged 45 years, was sent to me by Mr. Tudor Thomas with a diagnosis of sarcoma of the iris. He complained that his right eye was misty in the earlier part of the day and inclined to water. He thought that his right eye had become darker in colour during the last three months. Vision R. E. with -0.5 D.sph. $+1 \cdot 0$ D.cyl. axis vert. $=6 / 12 . \quad$ L. E. with +1.5 D.sph. $=6 / 6$.

On examination the whole iris had the washed out blue appearance of a long standing irido-cyclitis. The crypts between the iris stroma seemed uniformly dark in colour. There were iritic adhesions in the pupillary area. Down and out there were two raised swellings in the iris with the iris fibres stretched over them, they were slightly darker in colour than the iris and in front of them, towards the pupillary border were three folds in the iris concentric with the pupil. (Plate III.) The tension of the eye was +1 . By transillumination, a strong light being used, the swellings appeared to be translucent. As seen later, this was probably due to the fact that the ordinary transilluminating point was used and diffusion of the light took place around the tumour. Taking all 


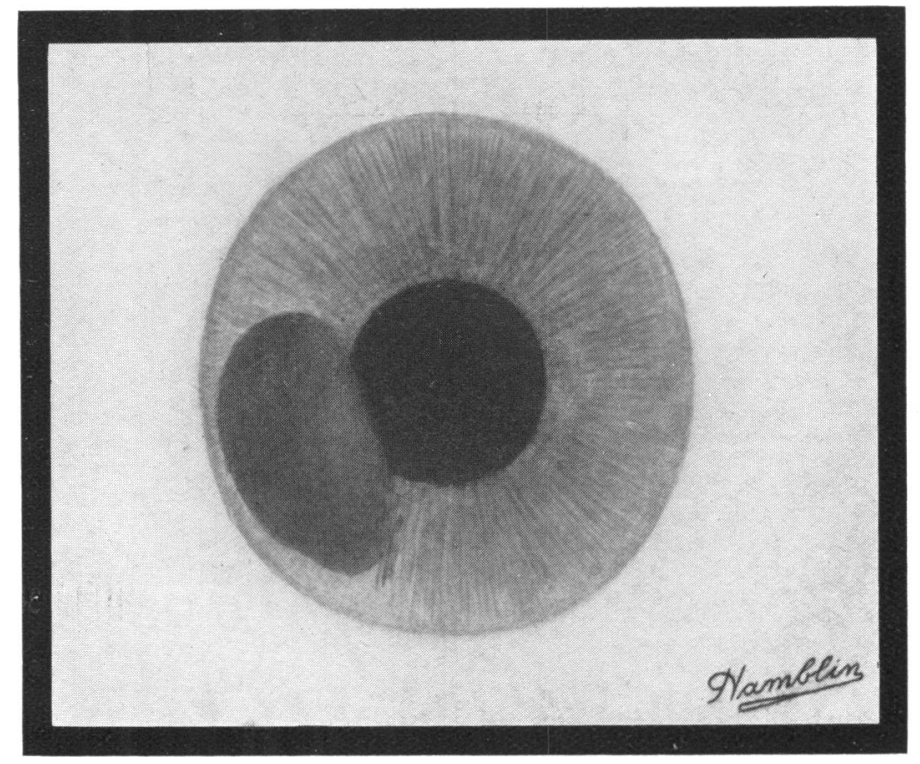

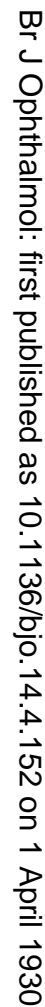

Plate I. Case I, 13 years before removal.

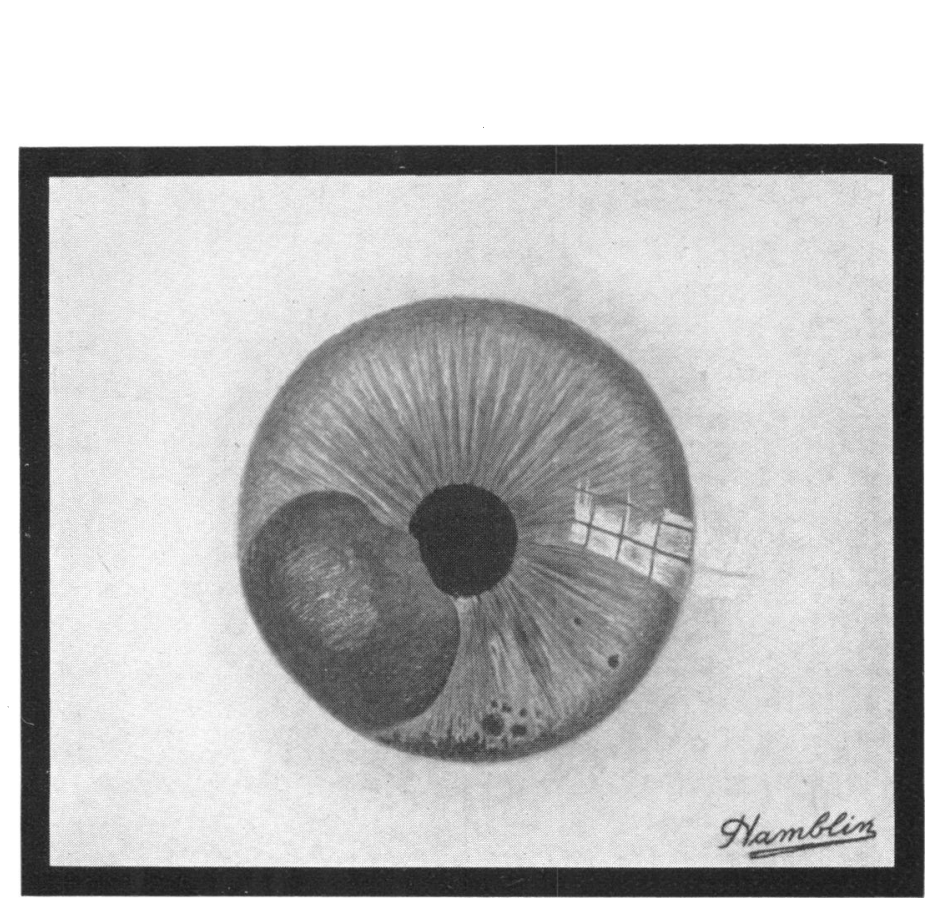

Plate II. Case I. 


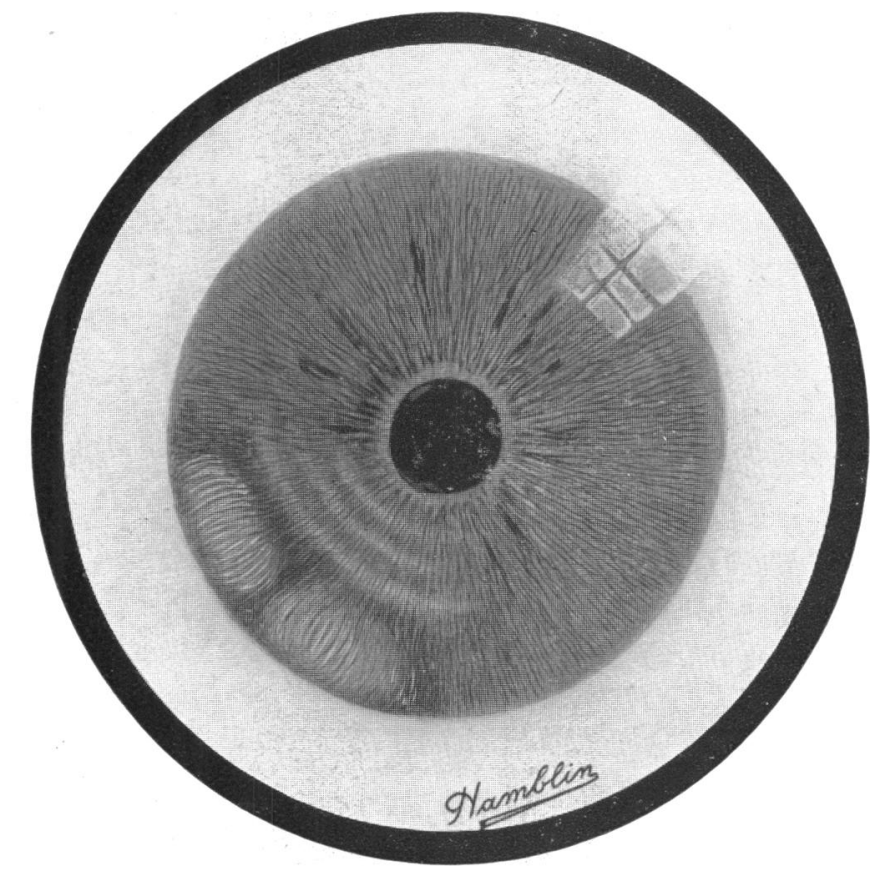

Plate III Case II.

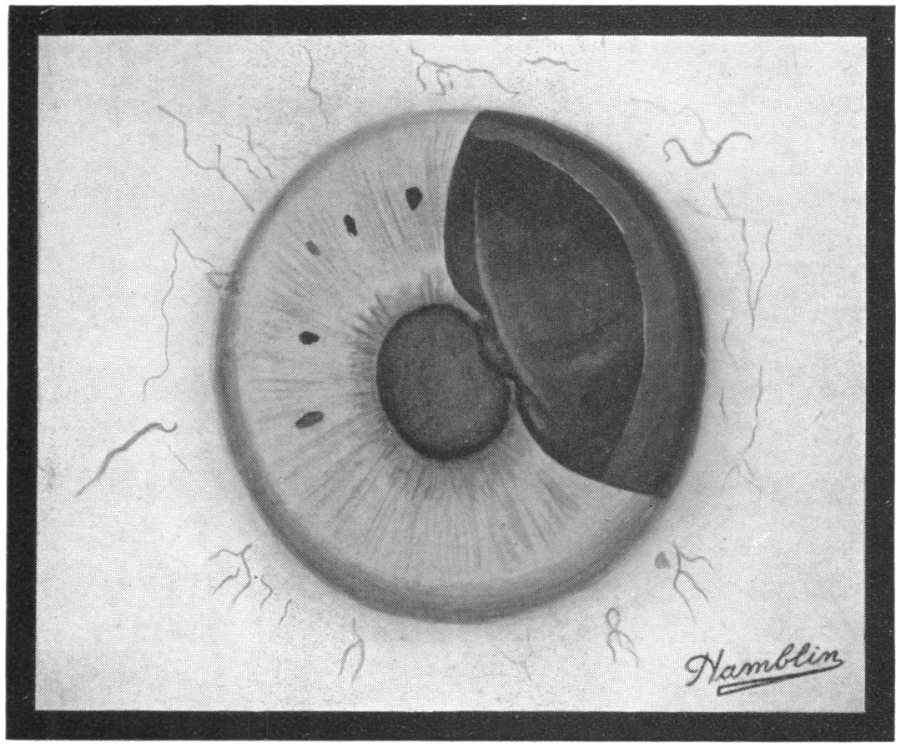

Piate IV. Case III. 
the points into consideration I thought the condition to be a cyst of the pigment epithelium. Having seen bad results from attempts to operate on cysts of the iris, eserine was first used and finally, on August 14, 1927, a trephining was performed at the upper corneo-scleral junction. The tension remained down until November, 192\%, when the trephine hole ceased to drain and Mr. Tudor Thomas again trephined the eye and the tension was relieved, the vision remaining as before at $6 / 12$.

On May 2, 1928, the tension again became raised although the filtration had not entirely ceased. The vision was $6 / 12$ and there was some contraction of the field to the nasal side. I saw him for the second time at the beginning of July, 1928. The whole iris had become much more deeply pigmented and the tension was +1 . The swelling in the iris did not appear to have increased in size at all. As the trephining evidently did not relieve the tension and the melanosis of the iris had become more marked, I advised removal of the eye, which was performed by Mr. Tudor Thomas. At the time of the removal of the eye, there were one or two pigmented spots on the surface of the conjunctiva above the trephine hole. These were not removed and have not increased in size since the operation.

\section{Pathological Examination.}

The eye was divided in an antero-posterior vertical direction. In the upper part of the limbus there was a trephine hole, but the root of the iris was firmly adherent to it and a pigmented mass appeared to block it. There was a peripheral iridectomy a little to one side of the hole. The iris was very dark in colour and there was a circumferential swelling of the iris blocking the angle of the anterior chamber. This swelling was dense black in colour and was solid. The whole anterior part of eye appeared deeply pigmented. There was pigment in the suspensory ligament of the lens, and on the lens capsule at the equator, and there was some indication of pigment in the region of the canal of Schlemm. There was a small patch of old anterior choroiditis, and the disc was deeply cupped. Half the eye was embedded in celloidin and sections made in the ordinary way. During the preparation the lens fell out of the specimen. The sections showed a darkly pigmented growth mainly situated in the lower angle of the anterior chamber and extending around its periphery in a ring-like manner. It apparently arose from the root of the iris and had spread back slightly in the ciliary body and had also involved the canal of Schlemm, spreading round the angle of the anterior chamber to the greater part of its circumference. The ciliary processes were somewhat flattened over the surface of the growth. The growth extended forward into the 
iris. Near the root of the iris it formed a small nodular mass, but over the surface of the iris it had spread superficially not involving the deep layers, but was seen by the naked eye to be deep to the superficial layers of the stroma of the iris and this no doubt accounted for the discoloration of the iris as seen clinically. Pigmentation had spread into the trephine hole and had blocked it and no doubt caused the rise in tension after the first trephining. Bleached sections showed that the tumour consisted of a large spindle cell growth of an endothelial type. Nearly all the cells of the tumour contained pigment. These large cells seem characteristic of sarcoma of the iris whether they have grown from a naevus which has previously been observed or not, and it is probable that this may have been the origin of the tumour. (Figs. 4, 5, 6, 7.)

In the following cases III and IV, it is doubtful whether the tumour started in the iris or ciliary body but the balance of evidence is in favour of the former.

\section{Case III}

C. D., aged 48 years. For 12 months she had noticed a spot on her right eye at the upper and inner side of the iris and during the last three months her vision had failed. On examination there was a black tumour situated at the upper and inner side of the iris and occupying about a third of its circumference. The tumour reached almost to the pupillary margin and bulged forward against the back of the cornea causing a disturbance in Descemet's membrane. No tumour could be seen behind the iris through the pupil. Tension, +1 . Vision, fingers. (Plate IV.)

The patient was admitted to the Central London Ophthalmic Hospital on October 28, 1928, and the eye was removed. The patient made an uninterrupted recovery. The eye was fixed in Zenker and bi-sected through the growth. A large growth was found occupying nearly the whole breadth of the iris and the anterior part of the ciliary body. It had destroyed the iris except near the pupillary margin and the anterior part of the ciliary body. It had invaded the canal of Schlemm and the angle of the chamber on either side of the tumour contained pigment cells. The tumour was commencing to cause distortion and displacement of the lens by pressure upon it. The tumour consisted of large endothelial-like cells, both pigmented and unpigmented, similar to those found in pigmented naevi. The anterior part of the tumour towards the pupillary margin showed considerable signs of degeneration and the remains of the iris in that neighbourhood were atrophic. Posteriorly the tumour had caused atrophy in the ciliary processes but the epithelium was still lying over the surface of the tumour. 
CASE I.

PIGMENTED NAEVUS OF THE IRIS BECOMING MALIGNANT.

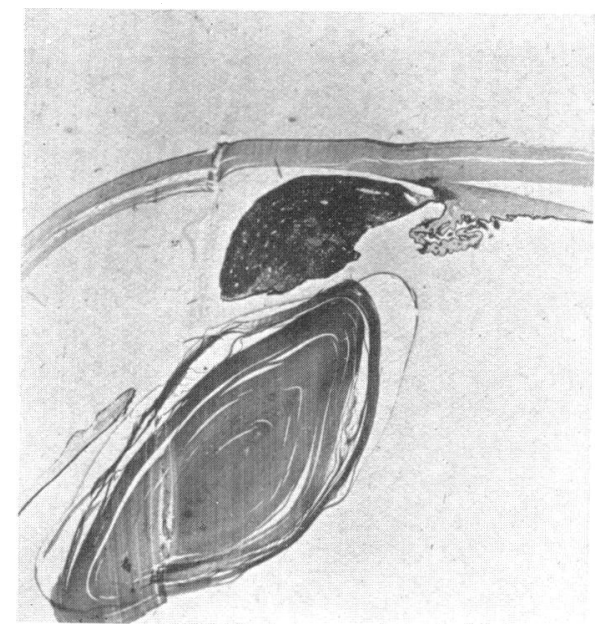

FIG. 1 .

The growth has ruptured through the posterior surface of the iris.

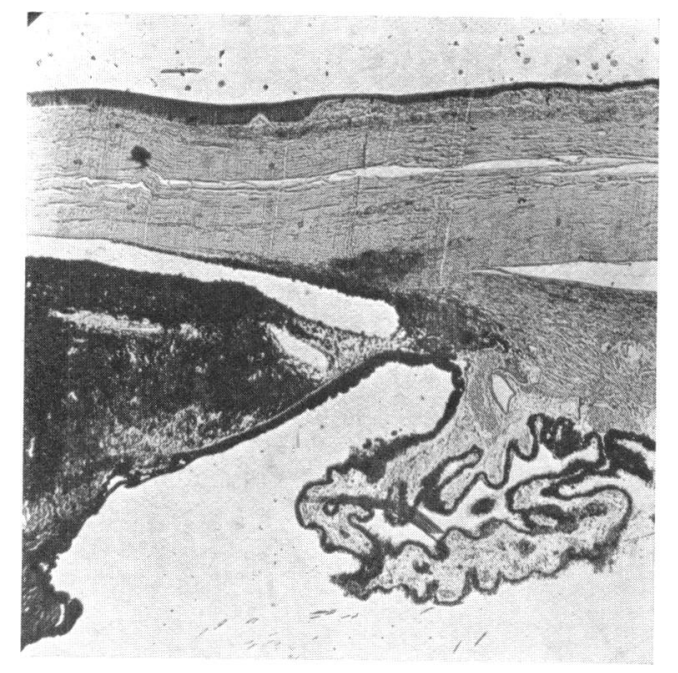

FIG. 2.

Showing the involvement of the angle of the anterior chamber. The growth starting to involve the canal of Schlemm and the ciliary body.

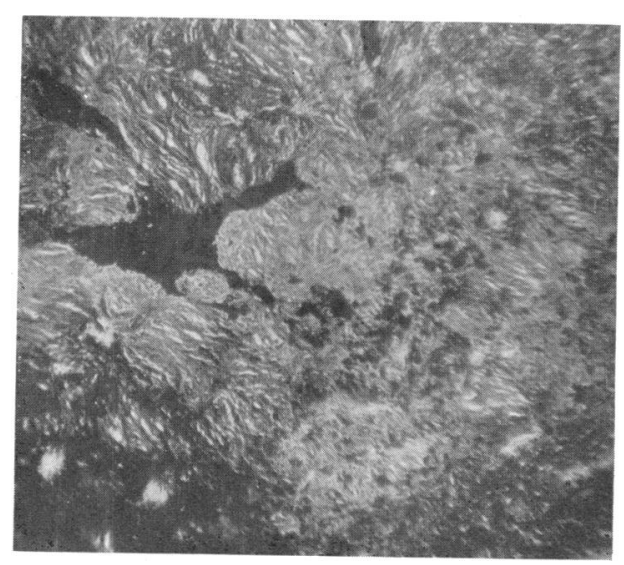

FIG. 3.

Showing the masses of pigment and large spindle cells composing the growth. 
CASE II.

RING SARCOMA OF THE IRIS.

FIG. 4.

The anterior part of the eye showing the growth in the angle of the chamber and pigment blocking the trephine hole.

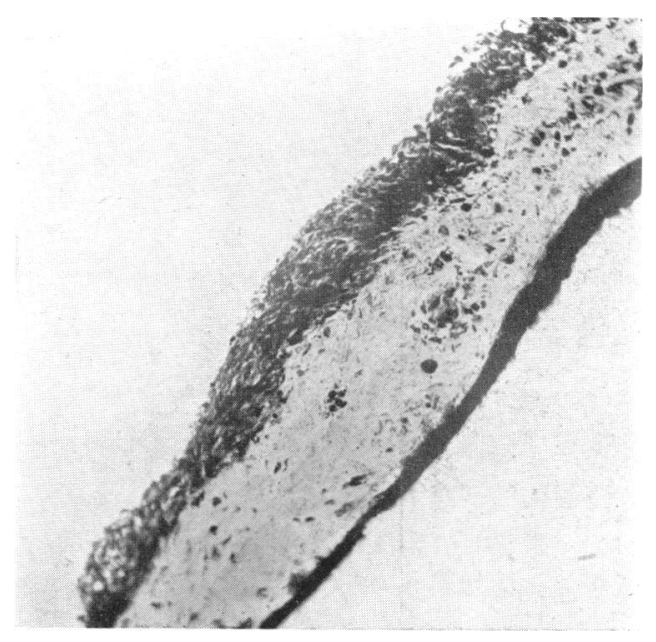

FIG. 6.

Showing the pigmentation spreading in the superficial layers of the iris.

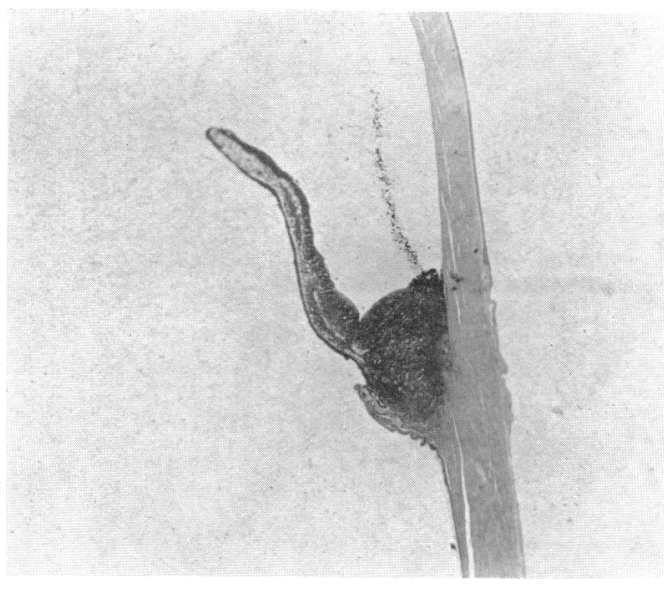

FIG. 5.

The pigmented growths in the angle of the chamber involving the ciliary body and canal of Schlemm.

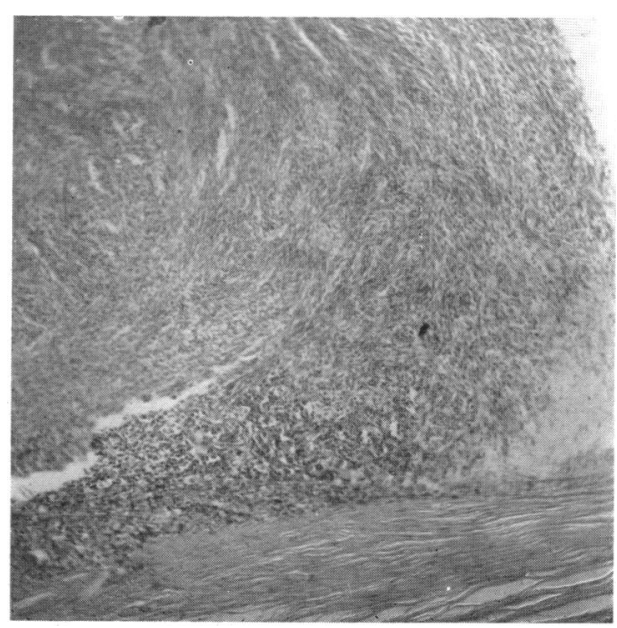

FIG. 7.

The growth composed of large spindle and pigment cells. 
CASE III.

MELANOTIC SARCOMA OF THE IRIS

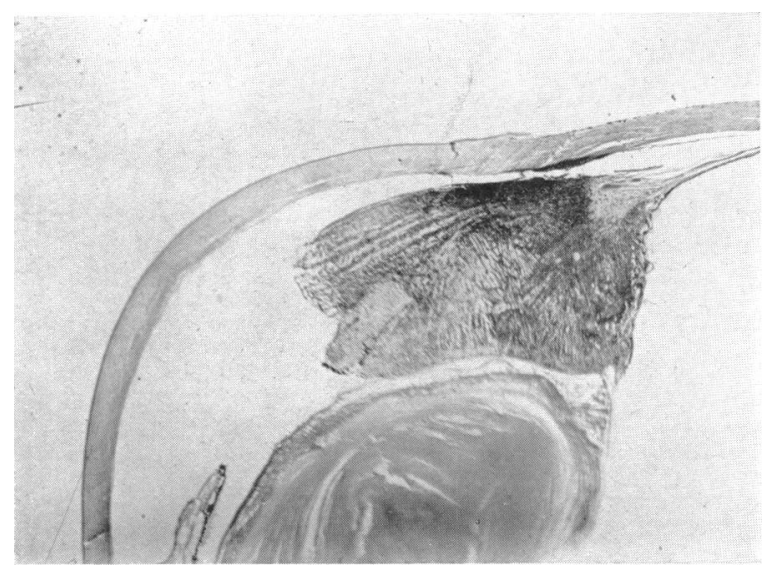

FIG. 8.

interior part of the eye showing a tumour of the iris vhich has ruptured through the posterior surface of the is and involved the ciliary body and suspensory ligament of the lens.

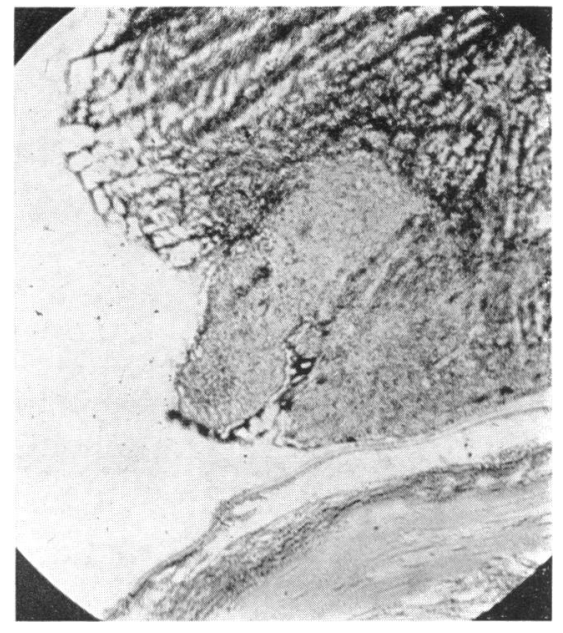

FIG 9.

Showing the pupillary margin of the iris which is atrophic. The tumour in this region has undergone considerable degenerative changes.

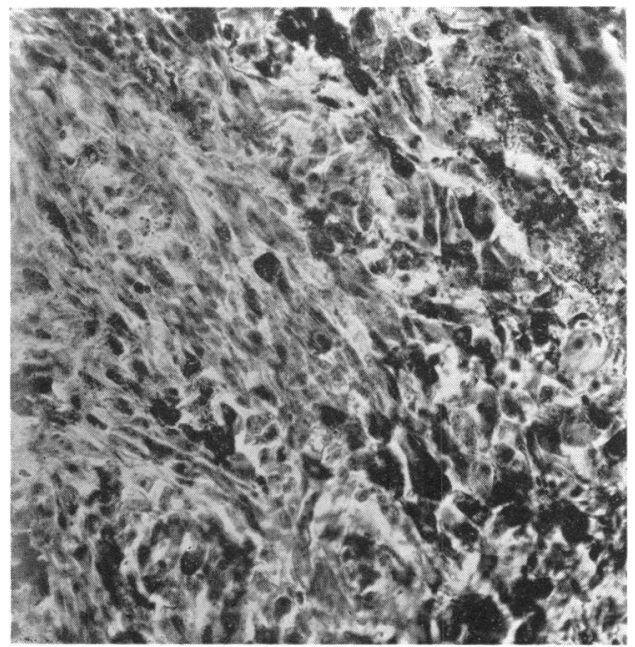

FIG. 10.

Showing the tumour composed of large spindle and pigment cells. 
CASE IV.

MELANOTIC SARCOMA OF THE IRIS.

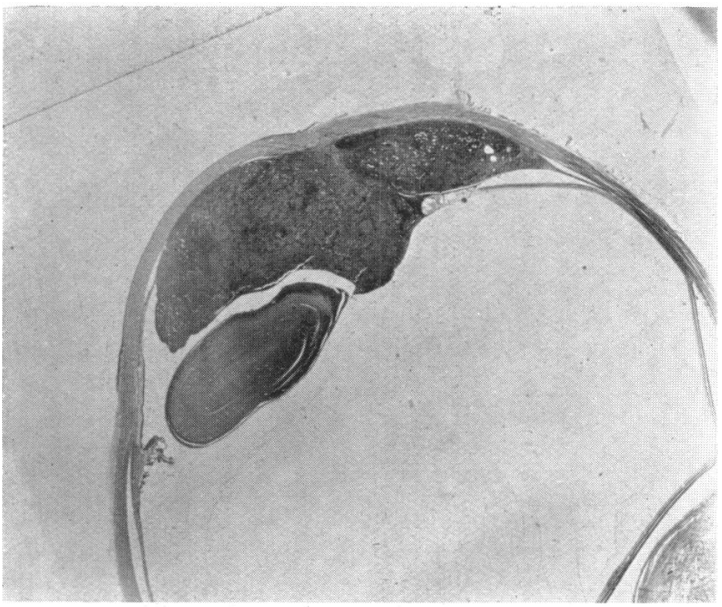

FIG. 11.

Melanotic sarcoma of the iris showing extensive involvement of the ciliary body, retina, suspensory ligament of the lens and deformation of the lens itself. 
The remainder of the iris showed no excess of pigment. (Figs. 8, $9,10$.

\section{Case IV. Mr. Bride's Case}

T. H., aged 44 years. Attended the Manchester Royal Eye Hospital on January 30,1928 . He said that three months previously he had injured his right eye with a flash from an electric welder, after which he noticed a dimness of vision. Right eye : no sign of injury. A large brown nodular mass was present in the anterior chamber at the nasal side. Transillumination showed this to be completely opaque. Vision 6/12. Tension normal. Left eye normal except for 3.5 dioptres of hypermetropia. Right eye was removed at the beginning of February with a long piece of optic nerve. The patient made an uninterrupted recovery. He had been examined by Dr. Donald Core, who could find no evidence of any secondary growths, and has remained well up to the present time.

The eye was bisected through the growth. The tumour was seen to occupy the whole breadth of the iris and ciliary body and was spreading backwards into the choroid. The pressure of the tumour had caused deformation of the lens and displacement away from the tumour, the fibres of the suspensory ligament were evidently relaxed and the lens had assumed a more spherical shape on the opposite side to the tumour. The iris was against the back of the cornea, but in spite of the angle being occluded, the clinical notes said that there was no increase of tension. The tumour consisted of large endothelial cells and contained a considerable amount of pigment. The ciliary body was completely atrophied and the tumour was actually invading the retina in the region of the ora serrata, the retina being oedematous and cystic as the tumour began to involve it. (Fig. Il.)

\section{Conclusions}

The above cases I think show the various stages of the disease and its mode of involving the surrounding structures. The early involvement of the canal of Schlemm leading to increase in tension is of great importance from a diagnostic point of view since it may be the only means of distinguishing an innocent from a malignant tumour. According to some authorities the loss of mobility of the iris is an important factor in diagnosis, but this I was not able to verify. Although the cases present varying clinical aspects, the histological changes so far as the cytoplasm of the cells is concerned are similar, which fact suggests that most of them have their origin in naevi. 